\title{
Low-Cloud Feedbacks from Cloud-Controlling Factors: A Review
}

\author{
Stephen A. Klein ${ }^{1}$ (D) Alex Hall ${ }^{2} \cdot$ Joel R. Norris $^{3} \cdot$ Robert Pincus $^{4,5}$
}

Received: 26 April 2017/Accepted: 21 September 2017/Published online: 24 October 2017

(C) The Author(s) 2017. This article is an open access publication

\begin{abstract}
The response to warming of tropical low-level clouds including both marine stratocumulus and trade cumulus is a major source of uncertainty in projections of future climate. Climate model simulations of the response vary widely, reflecting the difficulty the models have in simulating these clouds. These inadequacies have led to alternative approaches to predict low-cloud feedbacks. Here, we review an observational approach that relies on the assumption that observed relationships between low clouds and the "cloud-controlling factors" of the large-scale environment are invariant across time-scales. With this assumption, and given predictions of how the cloud-controlling factors change with climate warming, one can predict low-cloud feedbacks without using any model simulation of low clouds. We discuss both fundamental and implementation issues with this approach and suggest steps that could reduce uncertainty in the predicted low-cloud feedback. Recent studies using this approach predict that the tropical low-cloud feedback is positive mainly due to the observation that reflection of solar radiation by low clouds decreases as temperature increases, holding all other cloud-controlling factors fixed. The positive feedback from temperature is partially offset by a negative feedback from the tendency for the inversion strength to increase in a warming world, with other cloudcontrolling factors playing a smaller role. A consensus estimate from these studies for the contribution of tropical low clouds to the global mean cloud feedback is
\end{abstract}

Stephen A. Klein

klein21@1lnl.gov

1 Cloud Processes Research Group, Lawrence Livermore National Laboratory, 7000 East Avenue, L-103, Livermore, CA 94551, USA

2 Department of Atmospheric and Oceanic Sciences, University of California, Los Angeles, CA 90095, USA

3 Scripps Institution of Oceanography, University of California, San Diego, La Jolla, CA 92093, USA

4 Cooperative Institute for Research in Environmental Sciences, University of Colorado, Boulder, CO 80309, USA

5 Physical Sciences Division, NOAA Earth System Research Laboratory, Boulder, CO 80305, USA 
$0.25 \pm 0.18 \mathrm{~W} \mathrm{~m}^{-2} \mathrm{~K}^{-1}$ (90\% confidence interval), suggesting it is very unlikely that tropical low clouds reduce total global cloud feedback. Because the prediction of positive tropical low-cloud feedback with this approach is consistent with independent evidence from low-cloud feedback studies using high-resolution cloud models, progress is being made in reducing this key climate uncertainty.

Keywords Climate change $\cdot$ Cloud feedbacks $\cdot$ Low clouds

\section{Seeking Observational Constraints on Low-Cloud Feedbacks}

How clouds respond to the climate warming is a major uncertainty in climate change science that hinders prediction of the temperature sensitivity to radiative perturbations (Boucher et al. 2013). At the center of this uncertainty is the response of tropical oceanic low clouds, which is the single cloud type that explains the most spread of climate model predictions of cloud feedbacks (Bony and Dufresne 2005). A recent study estimates that low clouds globally explain around $50 \%$ of the inter-model variance of the global mean cloud feedback (Zelinka et al. 2016).

The widely varying responses of low clouds are perhaps unsurprising because climate models struggle to simulate these clouds. Tropical low clouds involve highly interactive processes of radiative transfer, turbulent and convective mixing and cloud physics that are imperfectly represented by climate model parameterizations. The parameterizations are necessary because the space and time-scales that climate models resolve are coarse relative to the space and time-scales of tropical low clouds.

The problems simulating low clouds motivate approaches to determine tropical lowcloud feedbacks that do not directly rely upon climate model simulations. One approach is to use large-eddy simulations that resolve low-cloud processes to predict the low-cloud changes forced by the climate changes in the environment (Rieck et al. 2012; Zhang et al. 2012; Blossey et al. 2013; Bretherton 2015). A second approach relies on observations of clouds to predict how they will respond to changes in the large-scale environment typical of climate warming. This observational approach is the subject of this paper.

At the heart of the observational approach is the fact that tropical low clouds are not randomly distributed but instead tend to vary with characteristics of the large-scale

(a) ISCCP Low Cloud Cover

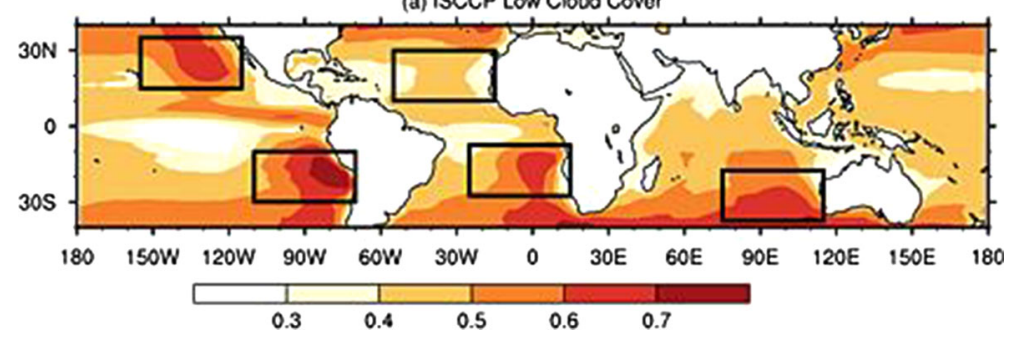

Fig. 1 Low-cloud cover from the International Satellite Cloud Climatology Project. Rectangles indicate the preferred regions of tropical low clouds of the stratocumulus type. These regions were studied in Q15, but they were also studied by M16, B16, and M17. Another common low-cloud type is trade cumulus which typically occur in the regions to the west of the rectangles in the figure. These clouds were studied directly by M17 and to some extent by B16. Low clouds are also common in the subsidence portions of the tropicalextra-tropical transition zone between $20^{\circ}$ and $40^{\circ}$ latitude in each hemisphere, and these clouds were studied in Z15 and M17. (Figure from Q15) 
environment (Fig. 1). The conditions that favor extensive sheets of low clouds such as stratocumulus include a relatively cold sea-surface temperature (SST) and a strong capping temperature inversion, among others. Elsewhere in the tropics, SST is warmer and the inversion weaker even as the air is still subsiding, favoring the smaller cloud fractions typical of trade cumulus clouds. Assuming low clouds are a response to their environment, environmental conditions influencing low clouds may be called "cloud-controlling factors" (Stevens and Brenguier 2009).

The basis of the observational approach for predicting low-cloud feedbacks from their controlling factors is the following: suppose we know how sensitive the clouds are to each cloud-controlling factor, as derived from observations of cloud variability in the present climate, and we have an idea of how each of the factors will change with climate warming, as derived from climate models and confirmed by physical reasoning. Then we can predict how the low clouds will change with climate warming under the assumption that the sensitivities of clouds to their controlling factors are time-scale invariant. This approach has been taken in five recent studies (Qu et al. 2015b; Zhai et al. 2015; Myers and Norris 2016; Brient and Schneider 2016; McCoy et al. 2017, in chronological order; hereafter these studies will be named "Q15," "Z15," "M16," "B16" and "M17," respectively). In this paper, we review these studies. From them we form a consensus estimate of the average tropical low-cloud feedback for marine subsiding regions (including both stratocumulus and trade cumulus) that can be used in an estimate of Earth's climate sensitivity. We also examine issues with this approach and how uncertainties in its predictions might be reduced.

\section{Cloud-Controlling Factors}

The studies considered make the assumption that anomalies in some measure of tropical low clouds $\Delta C$ relevant to radiative fluxes (such as low-cloud fraction or shortwave cloudradiative effect) can be represented by a first-order Taylor expansion in cloud-controlling factors $x_{i}$ :

$$
\Delta C=\left.\sum_{i} \frac{\partial C}{\partial x_{i}}\right|_{x_{j} \neq x_{i}} \Delta x_{i}
$$

In (1), the partial derivative $\frac{\partial C}{\partial x_{i}}$ represents the sensitivity of low clouds to a cloud-controlling factor and is assumed to be the same regardless of the time-scale over which anomalies are calculated ("time-scale invariant"). This time-scale is often inter-annual, but it could also be weekly or over decades and centuries. Any time-scale is valid provided it is greater than about 2-3 days, the longest time-scale over which the boundary layer and its clouds respond to changes in the cloud-controlling factors (Schubert et al. 1979; Bretherton 1993). Temporal averaging reduces but does not eliminate any disequilibrium between the clouds and their controlling factors.

Table 1 lists the most important controlling factors for tropical low clouds. The table also explains why tropical low clouds depend on each controlling factor, and cites a supporting observational and/or large-eddy simulation modeling study. While a wide body of research supports each factor, they do not all have the same level of theoretical understanding or observational and modeling support. The relationship of increased low cloud to increased inversion strength is the most robust relationship. Covariance between factors, such as free-tropospheric relative humidity with downward longwave radiative 
Table 1 Most prominent cloud-controlling factors affecting tropical low clouds, their physical explanation, and their support from observational and large-eddy simulation modeling studies

\begin{tabular}{|c|c|c|c|}
\hline $\begin{array}{l}\text { Cloud-controlling } \\
\text { factor }\end{array}$ & Physical explanation & $\begin{array}{l}\text { Observational } \\
\text { support }\end{array}$ & $\begin{array}{l}\text { Modeling } \\
\text { support }\end{array}$ \\
\hline $\begin{array}{l}\text { Strengthened } \\
\text { inversion } \\
\text { stability }\end{array}$ & $\begin{array}{l}\text { Reduced mixing across inversion keeps boundary } \\
\text { layer shallower, more humid and more cloudy }\end{array}$ & $\begin{array}{l}\text { Wood and } \\
\text { Bretherton } \\
(2006)\end{array}$ & $\begin{array}{l}\text { Bretherton } \\
\text { et al. (2013) }\end{array}$ \\
\hline $\begin{array}{l}\text { Reduced } \\
\text { subsidence }\end{array}$ & Deeper boundary layer increases cloud & $\begin{array}{l}\text { Myers and } \\
\text { Norris } \\
(2013)\end{array}$ & $\begin{array}{l}\text { Blossey et al. } \\
\text { (2013) }\end{array}$ \\
\hline $\begin{array}{l}\text { Increased } \\
\text { horizontal cold } \\
\text { advection }\end{array}$ & $\begin{array}{l}\text { Greater destabilization of the surface-atmosphere } \\
\text { interface increases upward buoyancy flux } \\
\text { promoting more clouds }\end{array}$ & $\begin{array}{l}\text { Norris and } \\
\text { Iacobellis } \\
(2005)\end{array}$ & N/A \\
\hline $\begin{array}{l}\text { Increased free- } \\
\text { tropospheric } \\
\text { humidity }\end{array}$ & $\begin{array}{l}\text { Entrainment drying is reduced, thus moistening the } \\
\text { boundary layer and increasing cloud }\end{array}$ & M16 & $\begin{array}{l}\text { van der } \\
\text { Dussen et al. } \\
\text { (2015) }\end{array}$ \\
\hline $\begin{array}{l}\text { Decreased } \\
\text { downward } \\
\text { longwave } \\
\text { radiation }\end{array}$ & $\begin{array}{l}\text { Reduced downward longwave radiation increases } \\
\text { cloud-top radiative cooling, driving more } \\
\text { turbulence supporting cloud }\end{array}$ & $\begin{array}{l}\text { Christensen } \\
\text { et al. (2013) }\end{array}$ & $\begin{array}{l}\text { Bretherton } \\
\text { et al. (2013) }\end{array}$ \\
\hline $\begin{array}{l}\text { Colder Sea-surface } \\
\text { temperature } \\
(S S T)\end{array}$ & $\begin{array}{l}\text { Colder temperature reduces the efficiency of } \\
\text { entrainment necessitating more cloud to produce } \\
\text { a given entrainment rate }\end{array}$ & Q15 & $\begin{array}{l}\text { Bretherton } \\
\text { and Blossey } \\
(2014)\end{array}$ \\
\hline $\begin{array}{l}\text { Increased surface } \\
\text { wind speed }\end{array}$ & $\begin{array}{l}\text { Increased surface driven shear mixing increases } \\
\text { latent heat flux and cloud }\end{array}$ & $\begin{array}{l}\text { Brueck et al. } \\
(2015)\end{array}$ & $\begin{array}{l}\text { Bretherton } \\
\text { et al. (2013) }\end{array}$ \\
\hline
\end{tabular}

In the first column, the direction of the cloud-controlling factor corresponds to that that would increase low clouds. Only the single most prominent study supporting the cloud-controlling factor is listed in the third and fourth columns

N/A indicates the absence of a study demonstrating the role of the factor in tropical low clouds

flux, makes it difficult to conclusively identify the individual role of some factors from observations, even if these are easily distinguished in modeling studies. Reliable largescale observations of some controlling factors are sometimes unavailable. It is unlikely that Table 1 is missing any important cloud-controlling factors since it includes the majority of the external large-scale variables in the energy and moisture budget equations for the boundary layer (Stevens and Brenguier 2009). Nonetheless, the list may be missing some known (e.g., aerosol) and unknown factors that likely only play a minor role in tropical low-cloud feedbacks to climate warming.

\section{Low-Cloud Feedbacks}

In the forcing-adjustment-feedback framework (Sherwood et al. 2015), changes in global mean top-of-atmosphere radiative flux $(R)$ due to individual feedbacks such as clouds are assumed to be linearly related to changes in global mean surface air temperature $\left(T_{\mathrm{g}}\right)$. The contribution of tropical low clouds to the global cloud feedback can be thought of as the product of the fraction of the planet dominated by tropical low clouds $(a)$ with the sensitivity to changes in $T_{\mathrm{g}}$ of the local cloud-induced changes in top-of-atmosphere radiation (e.g., using shortwave cloud-radiative effect): 


$$
\frac{\mathrm{d} R}{\mathrm{~d} T_{\mathrm{g}}}=a \frac{\mathrm{d} C}{\mathrm{~d} T_{\mathrm{g}}}
$$

If we view the local cloud response as resulting from changes in the local cloudcontrolling factors, we can use (1) to expand the local cloud feedback $\frac{\mathrm{d} C}{\mathrm{~d} T_{\mathrm{g}}}$ as:

$$
\frac{\mathrm{d} C}{\mathrm{~d} T_{\mathrm{g}}}=\sum_{i} \frac{\partial C}{\partial x_{i}} \frac{\mathrm{d} x_{i}}{\mathrm{~d} T_{\mathrm{g}}}
$$

In (3), the partial derivatives $\frac{\partial C}{\partial x_{i}}$ are the radiative sensitivities of cloud to the controlling factors and $\frac{\mathrm{d} x_{i}}{\mathrm{~d} T_{\mathrm{g}}}$ measures how each cloud-controlling factor $x_{i}$ varies with increases in $T_{\mathrm{g}}$ on climate change time-scales. Equation (3) expresses the concept that clouds respond to the local values of the cloud-controlling factors while cloud-controlling factors may depend on non-local factors (such as the large-scale circulation of the atmosphere), which can be (imperfectly) parameterized as a function of $T_{\mathrm{g}}$.

Multi-linear regression analysis of observations provides the sensitivities of clouds to their controlling factors on inter-annual or shorter time-scales (but no shorter than 8 days in the studies reviewed here), whereas analysis of climate model simulations reveals how the factors vary with long-term climate change. Cloud sensitivities can also be calculated from model simulations and compared to those calculated from observations on the timescales for which they are available.

Figure 2 shows the end result from one of the studies covered by this review (M16). In particular, panel (a) compares the local cloud feedback predicted by Eq. (3) (called "constrained") with that simulated by climate models (called "actual"); panel (b) shows each individual term from the right-hand side of Eq. (3). As Fig. 2 shows, M16 deduce a positive cloud feedback primarily because $\frac{\partial C}{\partial S S T}$ is positive in the satellite cloud observational datasets they use. However, the positive contribution from SST increases is offset by a negative contribution from changes in the Estimated Inversion Strength $(E I S)$. This contribution results from the facts that (1) climate models universally predict, with robust physical justification, that EIS will increase with warming (Webb et al. 2013; Qu et al. 2015a), and (2) cloud amount and the associated reflection of solar radiation increases strongly with increases in EIS in observations. EIS increases in warming simulations are driven by increased $S S T$ gradients between tropical low cloud and deep convection regions as well as increased land-ocean surface temperature contrast (Qu et al. 2015a). The other factors examined in M16, namely horizontal temperature advection, free-tropospheric humidity and subsidence, make smaller but collectively non-negligible negative contributions to the predicted cloud feedback.

The five studies in our review make different choices with respect to the observational datasets, cloud-controlling factors and spatiotemporal variability examined (Table 2). Despite these differences, the following commonalities emerge: (1) SST is the most important cloud-controlling factor for climate change cloud feedbacks; (2) tropical low clouds are observed to decrease in extent or radiative impact with increasing SST, leading to the prediction of positive tropical low-cloud feedbacks to climate change; (3) the four studies that consider EIS agree that although EIS contributes a negative feedback, it only partially offsets the positive feedback from SST; and (4) the three studies that consider additional factors beyond $E I S$ and $S S T$ agree that these additional factors collectively make only a minor contribution to tropical low-cloud feedback. 
Fig. 2 a Local tropical lowcloud feedback predicted from the observed sensitivity of clouds to their controlling factors (called "constrained") and that actually simulated by climate models; and b the components of the predicted cloud feedback from each controlling factor according to Eq. (3). The estimate in black is computing using the modelmean changes in factors and shows a $95 \%$ confidence interval calculated from the uncertainty in the cloud sensitivities calculated from observations. In panel $\mathbf{b}$ and for the constrained predictions in panel a, the spread in model predictions is due solely to intermodel differences in how cloudcontrolling factors change with rises in global mean surface air temperature. Symbol color classifies climate models according to how well they reproduce the observed cloud sensitivities (cyan = above average, orange $=$ average, red $=$ below average). Acronym definitions in the figure are:

"EIS"-Estimated Inversion Strength, "SSTadv"-horizontal temperature advection,

"RH700"-relative humidity at $700 \mathrm{hPa}$, "omega700"subsidence velocity at $700 \mathrm{hPa}$, and "SW CRE"-Shortwave Cloud-Radiative Effect.

(Figure from M16)

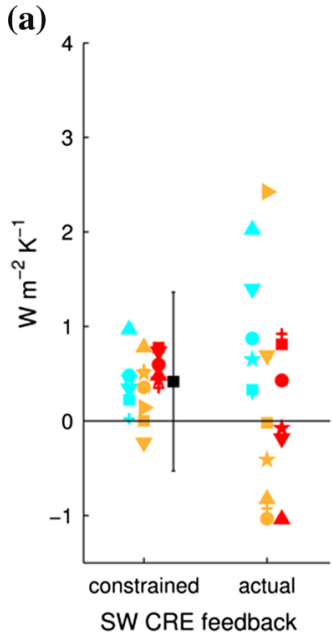

(b)

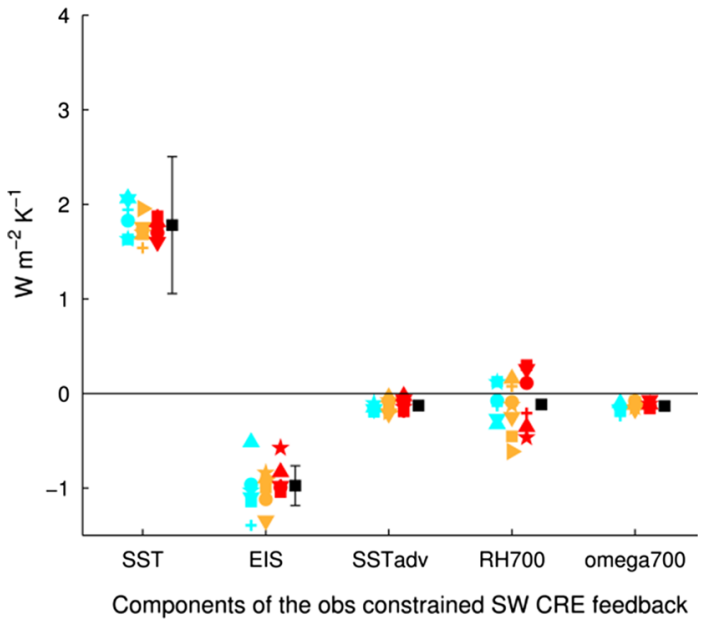

Figure 3 displays the quantitative predictions of the local tropical low-cloud feedback from these observationally based studies, along with values predicted from large-eddy simulations and global climate models; the "Appendix" explains how these predictions were derived. Some observational studies have more than one estimate because they consider multiple satellite cloud datasets (Q15 and M16), geographical areas (M17) or temporal scales of variability (B16). Nearly all observational estimates of the local tropical low-cloud feedback are positive and many values cluster near $1 \mathrm{~W} \mathrm{~m} \mathrm{~m}^{-2} \mathrm{~K}^{-1}$.

\section{Implications for Climate Sensitivity}

Do the cloud feedback estimates from the observational studies reviewed here help narrow the uncertainty in the climate change response of tropical low clouds? Local cloud feedback values from the cloud-controlling factor studies range from -1.0 to 
Table 2 List of observational cloud data, cloud-controlling factors, and the spatial-temporal variability examined in each study employing observations of clouds and their controlling factors to predict tropical low-cloud feedbacks

\begin{tabular}{|c|c|c|c|}
\hline Study & $\begin{array}{l}\text { Satellite cloud observations } \\
\text { used }\end{array}$ & $\begin{array}{l}\text { Cloud-controlling factors } \\
\text { included }\end{array}$ & $\begin{array}{l}\text { Variability used to define } \\
\text { cloud sensitivities }\end{array}$ \\
\hline $\begin{array}{l}\text { Qu et al. } \\
\text { (2015b)- } \\
\text { Q15 }\end{array}$ & $\begin{array}{l}\text { Cloud fraction observations } \\
\text { from ISCCP (1984-2009), } \\
\text { MISR (2000-2013), } \\
\text { MODIS (2002-2014), and } \\
\text { PATMOS-x (1982-2009) }\end{array}$ & $\begin{array}{l}\text { EIS and SST (model 1); EIS, } \\
\text { latent heat flux, specific } \\
\text { humidity lapse rate, free- } \\
\text { tropospheric humidity, } \\
\text { subsidence rate, surface } \\
\text { wind speed, and } \\
\text { horizontal temperature } \\
\text { advection (model 2) }\end{array}$ & $\begin{array}{l}\text { Inter-annual temporal } \\
\text { variability in the annual } \\
\text { means of the tropical low- } \\
\text { cloud regions containing } \\
\text { stratocumulus and cumulus } \\
\text { with stratocumulus (Fig. } 1 \text { ) }\end{array}$ \\
\hline $\begin{array}{l}\text { Zhai et al. } \\
\quad \text { (2015)- } \\
\text { Z15 }\end{array}$ & $\begin{array}{l}\text { Cloud fraction from merged } \\
\text { CloudSat and CALIPSO } \\
\text { data }(2006-2010)\end{array}$ & $S S T$ & $\begin{array}{l}\text { Seasonal cycle temporal } \\
\text { variability in the monthly } \\
\text { means averaged over } \\
\text { subsidence portions of the } \\
20^{\circ}-40^{\circ} \text { latitude band }\end{array}$ \\
\hline $\begin{array}{l}\text { Myers and } \\
\text { Norris } \\
(2016)- \\
\text { M16 }\end{array}$ & $\begin{array}{l}\text { Shortwave cloud-radiative } \\
\text { effect from CERES-EBAF } \\
(2000-2012) \text { and ISCCP- } \\
\text { FD (1984-1999) }\end{array}$ & $\begin{array}{l}E I S, S S T \text {, free-tropospheric } \\
\text { humidity, subsidence rate, } \\
\text { and horizontal } \\
\text { temperature advection }\end{array}$ & $\begin{array}{l}\text { Combined spatial and } \\
\text { temporal variability in the } \\
\text { inter-annual anomalies of } \\
\text { monthly means of tropical } \\
\text { low-cloud regions } \\
\text { containing stratocumulus } \\
\text { and cumulus with } \\
\text { stratocumulus }\end{array}$ \\
\hline $\begin{array}{l}\text { Brient and } \\
\text { Schneider } \\
\text { (2016)- } \\
\text { B16 }\end{array}$ & $\begin{array}{l}\text { Shortwave cloud-radiative } \\
\text { effect from CERES-EBAF } \\
\text { (2000-2015) and low- } \\
\text { cloud fraction from } \\
\text { CALIPSO-GOCCP } \\
\text { (2006-2014) }\end{array}$ & EIS and SST & $\begin{array}{l}\text { Temporal variability at } 3 \\
\text { time-scales (intra-annual, } \\
\text { seasonal cycle, and inter- } \\
\text { annual) and using inter- } \\
\text { annual anomalies in the } \\
\text { monthly means averaged } \\
\text { over geographically } \\
\text { varying tropical regions in } \\
\text { the lowest quartile of } \\
500 \mathrm{hPa} \text { relative humidity }\end{array}$ \\
\hline $\begin{array}{l}\text { McCoy } \\
\text { et al. } \\
\text { (2017)- } \\
\text { M17 }\end{array}$ & $\begin{array}{l}\text { Cloud fraction from MODIS } \\
(2002-2014)\end{array}$ & $\begin{array}{c}E I S, S S T, \text { free-tropospheric } \\
\text { humidity, subsidence rate, } \\
\text { and surface wind speed }\end{array}$ & $\begin{array}{l}\text { Combined spatial and } \\
\text { temporal variability in } \\
\text { 8-day mean data within } 3 \\
\text { oceanic regions: } 40^{\circ} \mathrm{N}- \\
40^{\circ} \mathrm{S} \text {, trade cumulus, and } \\
\text { mixed stratocumulus and } \\
\text { trade cumulus regions }\end{array}$ \\
\hline
\end{tabular}

Acronym definitions and references for the satellite cloud observations are: ISCCP International Satellite Cloud Climatology Project (Rossow and Schiffer 1999), MISR Multiangle Imaging SpectroRadiometer (Marchand and Ackerman 2010), MODIS Moderate Resolution Imaging Spectroradiometer (Platnick et al. 2003), PATMOS-x Pathfinder Atmospheres Extended (Foster and Heidinger 2013), merged CloudSat/ Calipso (Mace et al. 2009), CERES-EBAF Clouds and the Earth's Radiant Energy System Energy Balanced and Filled (Loeb et al. 2009), ISCCP-FD International Satellite Cloud Climatology Project Radiative Flux Dataset (Zhang et al. 2004), and CALIPSO-GOCCP Cloud-Aerosol Lidar and Infrared Pathfinder Satellite Observations GCM-Oriented CALIPSO Cloud Product (Chepfer et al. 2010) 


\section{Tropical Low-Cloud Feedbacks}

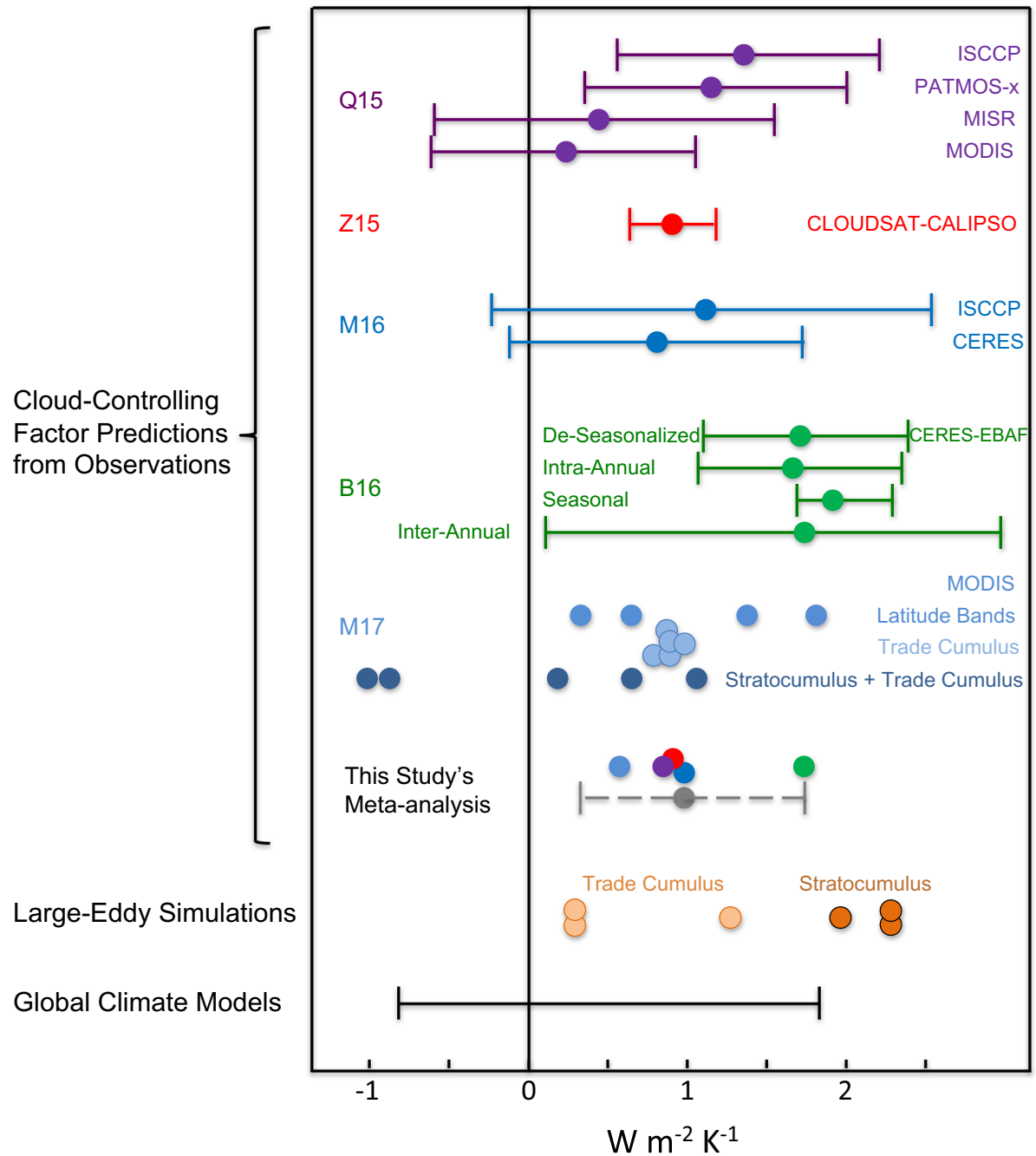

Fig. 3 Values of local tropical low-cloud feedbacks predicted from recent observational studies, large-eddy simulations and global climate models. Local feedbacks are defined as the local change in top-of-atmosphere radiation from tropical low clouds per degree increase in global mean surface air temperature. Bar widths for observational studies (unavailable for M17) and this study's meta-analysis represent $90 \%$ confidence intervals. Values from individual large-eddy simulation studies are shown. The bar width for global climate models indicates the range of model results. See the "Appendix" for details

$+1.9 \mathrm{~W} \mathrm{~m}^{-2} \mathrm{~K}^{-1}$. This range would appear to offer no constraint on the climate model range, -0.8 to $+1.8 \mathrm{~W} \mathrm{~m}^{-2} \mathrm{~K}^{-1}$, as seen in Fig. 3. Still it is worth recognizing that many observational estimates are concentrated in a narrower range. We synthesize these results to form a consensus estimate through a meta-analysis of these studies. A formal approach would consider the uncertainty of each study and account for their degree of independence, but measures of uncertainty are not supplied uniformly for these studies, 
and no confidence intervals are supplied by M17 at all. Instead we proceed approximately by assuming that each study represents a partially independent result, which we justify by noting the diversity of observational satellite cloud datasets, geographic domains, and time periods employed. We also assume that each study gives a representative estimate of the cloud feedback averaged over tropical low-cloud regions; this is further discussed below (issue I3). Our consensus estimate is made by averaging all central estimates to form a single value of cloud feedback for each study (shown near our meta-estimate in Fig. 3). Then we compute the five-study mean and $90 \%$ confidence interval as 1.645 times the sample standard deviation, consistent with a normal distribution. The meta-analysis uncertainty describes the uncertainty across the ansätze employed by each of the five studies but not the uncertainty within each study. Nonetheless, this uncertainty estimate seems appropriate as it produces a $90 \%$ confidence interval whose width is within $10 \%$ of the average interval width in individual studies shown in Fig. 3.

The meta-analysis produces a local tropical low-cloud feedback of $1.0 \pm 0.7 \mathrm{~W} \mathrm{~m}^{-2} \mathrm{~K}^{-1}$. Our estimate suggests that climate models with negative tropical low-cloud feedback are unrealistic, but still leaves an uncertainty range of $\sim 50 \%(=1.4$ / 2.6) of that of current climate models.

To determine how the local response of tropical low clouds contributes to climate sensitivity, we first calculate the tropical low-cloud contribution to global cloud feedback by multiplying the local cloud feedback by the fraction of the planet covered by tropical low-cloud regions, following (2). Under the assumptions that (a) subsidence regions cover $2 / 3$ of the tropical oceans, (b) oceans cover $3 / 4$ of the tropics, and (c) the tropics cover $1 / 2$ of the planet, we estimate that tropical oceanic subsidence regions cover approximately $1 / 4$ of the planet $(a=1 / 4)$. Thus, we arrive at a contribution of tropical low clouds to the global mean cloud feedback of $0.25 \pm 0.18 \mathrm{~W} \mathrm{~m}^{-2} \mathrm{~K}^{-1}$.

We then calculate an approximate equilibrium climate sensitivity ECS according to $E C S=F_{2 \mathrm{CO}_{2}} /(-\lambda)$, where $F_{2 \mathrm{co}_{2}}$ is the effective radiative forcing for a doubling of carbon dioxide $\left(\mathrm{CO}_{2}\right)$ and $\lambda$ is the climate feedback parameter (Dufresne and Bony 2008). The climate feedback parameter is equal to the sum of the Planck response and feedbacks from water vapor, lapse, surface albedo and clouds. We use average climate model values for the forcing and non-cloud feedbacks as reported in Caldwell et al. (2016) (Table 3). Further assuming a high-cloud altitude feedback (Zelinka et al. 2016) of $+0.2 \mathrm{~W} \mathrm{~m}^{-2} \mathrm{~K}^{-1}$, but no other cloud feedbacks, we compute an ECS of $2.4 \mathrm{~K}$. Adding the central estimate of $+0.25 \mathrm{~W} \mathrm{~m}^{-2} \mathrm{~K}^{-1}$ for the tropical low-cloud feedback from our meta-analysis to the high-cloud altitude feedback, we arrive at a central estimate for ECS of $3.0 \mathrm{~K}$. Thus, if the tropical low-cloud feedback is positive with the magnitude suggested by these observational studies, ECS would be in the middle of its canonical range of 1.5-4.5 K (Stocker et al. 2013).

\section{Sources of Uncertainty}

In interpreting cloud feedbacks derived from observations of clouds and their controlling factors, a number of issues merit discussion. We roughly divide these into two categories: those of a fundamental nature $(F 1-F 4)$ that may limit the validity of this observational approach, and those related to implementation (II-I5) that may limit the accuracy of the feedback estimated with a presumed valid approach. The latter issues, if addressed, might allow for tighter constraints on tropical low-cloud feedback. 
Table 3 Values of the $\mathrm{CO}_{2}$ radiative forcing and various feedbacks used in the calculation of equilibrium climate sensitivity

\begin{tabular}{lr}
\hline Term & \multicolumn{1}{l}{ Value } \\
\hline Radiative forcing for doubling of $\mathrm{CO}_{2}$ concentration $\left(F_{2 \mathrm{CO}_{2}}\right)$ & $3.43 \mathrm{~W} \mathrm{~m}^{-2}$ \\
Planck feedback & $-3.15 \mathrm{~W} \mathrm{~m}^{-2} \mathrm{~K}^{-1}$ \\
Water vapor feedback & $1.69 \mathrm{~W} \mathrm{~m}^{-2} \mathrm{~K}^{-1}$ \\
Lapse rate feedback & $-0.53 \mathrm{~W} \mathrm{~m}^{-2} \mathrm{~K}^{-1}$ \\
Surface albedo feedback & $0.38 \mathrm{~W} \mathrm{~m}^{-2} \mathrm{~K}^{-1}$ \\
High-cloud altitude feedback & $0.20 \mathrm{~W} \mathrm{~m}^{-2} \mathrm{~K}^{-1}$ \\
\hline
\end{tabular}

These values are the multi-model-mean values from Caldwell et al. (2016) computed by linear regression of the first 150 years of the abrupt quadrupling of $\mathrm{CO}_{2}$ climate model experiments. As such, the forcing is an effective radiative forcing that includes the rapid cloud adjustments. The values are averaged only for models passing the clear-sky linearity test used to test the accuracy of the radiative kernel approach to quantify feedbacks. See Caldwell et al. (2016) for details

\subsection{Fundamental Issues}

\subsubsection{F1. Are Cloud Sensitivities Time-scale Invariant?}

The approach used in these five studies relies heavily on the assumption that the sensitivity of clouds to their controlling factors remains constant across any time-scale longer than a few days - the longest time-scale over which the boundary layer is still in a state of transient adjustment to changes in the cloud-controlling factors. We can test this proposition by examining results from studies that consider multiple time-scales. B16 calculates sensitivities at 3 time-scales: intra-annual, seasonal cycle, and inter-annual (from monthly mean data). Table 5 indicates consistency (within their uncertainty estimates) across these time-scales for the SST sensitivity. Although this is less true for the EIS sensitivity, the final estimates of their cloud feedback are still consistent across time-scale (Fig. 3). M17 calculates sensitivities at 2 time-scales: using 8-day means and annual means. They find that the sensitivities vary by less than a factor of two between those two time-scales, with one exception, namely for $\frac{\partial C}{\partial S S T}$ from the regions of mixed stratocumulus and trade cumulus. Because M17 do not supply uncertainty coefficients, one cannot judge if this difference is significant. Separately, deSzoeke et al. (2016) make a thorough analysis of the time-scale dependence of the relationship between low cloud and EIS, finding that while the amount of low-cloud variance explained by EIS varies with time-scale, the sensitivity of low cloud to $E I S$ varies by less than a factor of two between daily, monthly, and inter-annual timescales examined. Klein (1997) examined low-cloud variability at a single point in the Northeast Pacific and found that the signs of the correlation coefficients between low-cloud fraction and several controlling factors remain fixed across time-scales from daily to monthly. Some variations in the cloud sensitivities are expected due to statistical uncertainty in sensitivity coefficients, and from this available evidence one cannot disprove the notion that cloud sensitivities are time-scale invariant. Certainly the sensitivities agree qualitatively and in sign across time-scales, if not in exact magnitude. To fully address this question, more observational studies calculating cloud sensitivities with error estimates at multiple time-scales are needed. 


\subsubsection{F2. Are Clouds Responding to the Controlling Factors?}

When regression analysis is applied to observations to derive sensitivity coefficients, it is assumed that these reflect the influence of the factors on the clouds, rather than the influence of the clouds on the factors. But how confident are we that this is the case? This concern is most obviously relevant for variables internal to the boundary layer. For example, relative humidity in the boundary layer or the state of cloud organization would be questionable candidates for a controlling factor and is not listed in Table 1 for this reason. For the cloud-controlling factors listed in Table 1, substantial observational evidence exists that cloud properties are best correlated to upwind (Klein et al. 1995; Klein 1997; Mauger and Norris 2010) or earlier (deSzoeke et al. 2016) sampling of the factors. These lines of evidence reinforce the notion that these quantities are external and largescale characteristics of the atmosphere or ocean which influence the boundary layer and its clouds, rather than the other way around.

The relationship between clouds and SST deserves extra discussion in this connection, given the major role for $\frac{\partial C}{\partial S S T}$ in determining tropical low-cloud feedback. Modeling studies demonstrate that a positive radiative feedback from tropical low clouds can amplify low frequency (multi-year and decadal) SST variability (Bellomo et al. 2014, 2015), so there is no doubt that clouds affect SST. Nonetheless, it is also clear from large-eddy simulations (Blossey et al. 2013) and observational evidence (Klein et al. 1995; Klein 1997; Mauger and Norris 2010) that clouds respond to SST over just a few days. For an ocean mixed-layer depth of $50 \mathrm{~m}$, it takes about 300 days to produce an SST anomaly in response to cloudradiative anomalies that is consistent with the observed value of $\frac{\partial C}{\partial S S T}$ (deSzoeke et al. 2016); covariations of cloud with SST at time-scales shorter than 300 days would therefore reflect the influence of SST on cloud, and not the other way around. The fact that M17 find similar values of $\frac{\partial C}{\partial S S T}$ at 8 -day time-scales as at inter-annual time-scales (with the exception of the region with mixed stratocumulus and trade cumulus) suggests that two-way interactions between cloud and $S S T$ do not cause $\frac{\partial C}{\partial S S T}$ to be different at the longer time-scales. Furthermore, climate model simulations with prescribed $S S T$, which by definition do not have the two-way interactions of clouds and $S S T$, produce a value of $\frac{\partial C}{\partial S S T}$ reasonably close to those derived from simulations with fully coupled ocean-atmosphere models (X. Qu personal communication).

To understand the reason for this similarity across time-scales, we appeal to our understanding of the water vapor feedback. One expects water vapor anomalies to adjust to changes in the underlying $S S T$ so that relative humidity is approximately conserved. One expects this to be true even if water vapor did not produce the longwave radiative anomalies that fed back on the SST changes. Thus, the diagnosed sensitivity of water vapor to surface temperature is the same, whether the interaction is one-way or two-way. In a similar way, we may also think of cloud anomalies as being in a state of mutual adjustment with underlying $S S T$, so as to maintain a boundary layer that is thermodynamically consistent with its environment. This would be the case whether or not SST has enough time to be affected by the top-of-atmosphere energy budget perturbation that the cloud anomaly produces. 


\subsubsection{F3. Uncertainty in the Climate Change Prediction of Cloud-Controlling Factors}

The cloud-controlling factors are among the more trustworthy variables of climate models because they are aspects of the resolved large-scale state. While climate models generally agree on their predicted climate changes, any inter-model spread contributes to spread in the predicted low-cloud feedback with this observational approach. This can be seen in Fig. 2, where the spread among climate models (which are displayed as colored symbols) for the "constrained" column in panel a and for each factor in panel b arises solely from inter-model spread in the climate changes in cloud-controlling factors $\frac{\mathrm{d} x_{i}}{\mathrm{~d} T_{\mathrm{g}}}$. For the total feedback ("constrained" column in panel a), inter-model spread is comparable to, but slightly smaller than the spread due to the uncertainty in the observed cloud sensitivities (shown by the black uncertainty bar). Comparison to panel $b$ indicates that much of the total feedback spread is due to inter-model differences in the predicted changes in EIS and free-tropospheric humidity. For $S S T$ - the factor with the largest average cloud feedback contribution-inter-model spread in $\frac{\mathrm{d} S S T}{\mathrm{~d} T_{\mathrm{g}}}$ in the period examined (121-140 years after $\mathrm{CO}_{2}$ quadrupling) is smaller than the uncertainty in the observed value of $\frac{\partial C}{\partial S S T}$. We conclude from this figure, as well as the analysis of Q15, that the uncertainty in the predicted climate change of the cloud-controlling factors is a significant component of the cloud feedback uncertainty but not quite as large as the uncertainty in $\frac{\partial C}{\partial S S T}$. Reducing this uncertainty would include diagnosing the influences on the cloud-controlling factors and identifying constraints on the climate-model-simulated changes. A step in this direction for EIS was taken by Qu et al. (2015a). Also, a preliminary investigation finds that the normalized changes in SST and associated cold advection are positively correlated across models with the low-cloud feedback itself (Tim Myers, personal communication). This correlation is consistent with more positive low-cloud feedbacks locally warming the ocean more (relative to the global mean temperature increase). Normalized changes in other cloud-controlling factors including free-tropospheric humidity, subsidence and EIS do not have an apparent relationship to the low-cloud feedback itself, consistent with the expectation that their large-scale nature makes them additionally sensitive to remote influences. Until this uncertainty is reduced, the "constrained" column in Fig. 2a suggests that the uncertainty in the local cloud feedback will not be smaller than $\pm 0.5 \mathrm{~W} \mathrm{~m}^{-2} \mathrm{~K}^{-1}$. While this uncertainty is considerably smaller than that of the individual observational estimates in Fig. 3, it is not very much smaller than the $\pm 0.7 \mathrm{~W} \mathrm{~m}^{-2} \mathrm{~K}^{-1}$ uncertainty in our meta-estimate.

\subsubsection{F4. Time-Dependency of Cloud-Controlling Factors During a Climate Change}

Our cloud feedbacks estimates have been made under the assumption that changes in cloud-controlling factors $\frac{\mathrm{d} x_{i}}{\mathrm{~d} T_{\mathrm{g}}}$ are constant in time. A growing body of evidence (Andrews et al. 2015; Rugenstein et al. 2016) suggests that cloud feedbacks to climate change are sensitive to the spatial pattern of SST warming, which evolves during simulated timedependent climate change. Of particular importance to tropical low-cloud feedbacks is the differential rate of warming between tropical ascent and subsidence regions: if tropical ascent regions initially warm more rapidly than tropical subsidence regions, EIS in tropical subsidence regions will increase through the influence of the large-scale circulation (Caldwell and Bretherton 2009; Qu et al. 2015a). This will contribute to low cloud 
increases and hence smaller low-cloud feedbacks (Zhou et al. 2016). When more warming later appears in the subsidence regions, tropical low-cloud feedbacks will become more positive. This behavior is most apparent in the simulations with abrupt quadrupling of $\mathrm{CO}_{2}$ (Andrews et al. 2015; Rugenstein et al. 2016), but it also occurs in decadal feedbacks inferred for the last century (Gregory and Andrews 2016; Zhou et al. 2016). This does not negate the framework of Eqs. (1-3). Rather it suggests that there would be value in allowing that the $\frac{\mathrm{d} x_{i}}{\mathrm{~d} T_{\mathrm{g}}}$, especially $\frac{\mathrm{d} E I S}{\mathrm{~d} T_{\mathrm{g}}}$ and $\frac{\mathrm{d} S S T}{\mathrm{~d} T_{\mathrm{g}}}$, might vary with time, even as the cloud sensitivities $\frac{\partial C}{\partial x_{i}}$ to local conditions remain constant.

As interesting as SST pattern effects are, they are unlikely to have a first-order impact on the century time-scale tropical low-cloud feedback. With typical values of the cloud sensitivities, a negative tropical local low-cloud feedback would not occur unless the ratio of EIS to SST change is 1, several times larger than the typical ratio of 0.2 exhibited by climate models. Such a large value might happen for decadal variability (Zhou et al. 2016), but is extremely unlikely to happen for century time-scale warming. Oceanic heat transport on the century time-scale prevents warming in tropical subsidence regions from differing much from warming in tropical ascent regions. For century time-scale forced climate change such as $100+$ years after abrupt quadrupling of $\mathrm{CO}_{2}$ or by the end of the twentyfirst century in a scenario simulation, the values of cloud-controlling factors simulated by climate models are such that the tropical low-cloud feedbacks are decidedly positive, given the observed cloud sensitivities.

\subsection{Implementation Issues}

\subsubsection{I1. Imperfect Observations of Clouds and Their Controlling Factors}

Figure 3 shows that the central estimate spread among the four satellite cloud fraction datasets in Q15 is $1.1 \mathrm{~W} \mathrm{~m}^{-2} \mathrm{~K}^{-1}$, but the spread among two satellite cloud-radiative effect datasets in M16 is only $0.4 \mathrm{~W} \mathrm{~m}^{-2} \mathrm{~K}^{-1}$. Such differences could arise from uncertainties in cloud observations. Indeed, the five studies in this review employed a wide range of satellite-derived cloud metrics, including estimates of cloud fraction and shortwave cloud-radiative effect (Table 2). However, the effect of these choices on cloud feedback estimates is difficult to determine. Q15 and M16 use multiple cloud datasets, but the datasets cover different years, and thus differences are not solely due to measurement or algorithmic changes. The larger spread among Q15 estimates might be consistent with the fact that cloud fraction is more difficult to measure. As a result, there may be greater differences between cloud fraction datasets than those describing cloud-radiative effect (Maddux et al. 2010; Pincus et al. 2012).

The differences in feedback estimates could also come from observational uncertainty in cloud-controlling factors. Unfortunately, no study has quantified this effect. SST is extremely well-observed from satellite, but observational uncertainty might be not negligible for the other factors that often rely on reanalysis data (Pincus et al. this issue). For example, M17's estimate of $\frac{\partial C}{\partial E I S}$ using satellite EIS observations appears consistent with M16's estimate using EIS from reanalysis data. But this is not a clean comparison because the satellite observations are used in data assimilation, among other reasons.

Clearly, more research into the impact on predicted low-cloud feedbacks of observational uncertainty in clouds and their controlling factors would be helpful. At the same time, because the error bars on low-cloud feedback estimates derived from diverse cloud 
and cloud-controlling factors overlap substantially, we judge it unlikely that estimates of cloud feedback would change significantly if observational uncertainties in cloud or cloudcontrolling factors were better quantified and reduced.

\subsubsection{I2. Limited Duration of the Observational Record}

The majority of studies use inter-annual variability to determine $\frac{\partial C}{\partial S S T}$ and $\frac{\partial C}{\partial E I S}$, and the typical length (15-25 years) of the more reliable satellite records offers very limited numbers of independent samples. This suggests the limited duration of the observational record is a major contributor to uncertainty in the estimates shown in Fig. 3. A compounding problem arises from the covariance of EIS and SST for current climate variability on monthly and longer time-scales. However, the uncertainty in $\frac{\partial C}{\partial E I S}$ is probably smaller than the uncertainty in $\frac{\partial C}{\partial S S T}$ because sub-monthly variations of EIS, which typically do not co-occur with large SST fluctuations, confirm the value of the EIS sensitivity (M17, deSzoeke et al. 2016). As time goes by, longer satellite records will gradually reduce uncertainty in $\frac{\partial C}{\partial S S T}$ due to limited observational duration.

\subsubsection{I3. Limited Spatial Sampling of the Observations}

The results of large-eddy simulation suggest a systematic difference in the cloud feedback between regions dominated by trade cumulus and regions dominated by stratocumulus (Fig. 3). Three of the observational studies used here, however, (Q15, M16, B16) primarily analyze variations in the stratocumulus regions. These studies' estimates of low-cloud feedback may be biased because they do not sample trade cumulus that might have a smaller feedback. However, M17's feedback for trade cumulus is close to our meta-estimate and is in fact larger than their feedback for stratocumulus regions. The observational analysis for latitude bands in M17 and Z15 also produces feedbacks that do not depart significantly from our meta-estimate. For individual cloud sensitivities, M17 found general agreement between regions for most factors, with the exception of subsidence (Myers and Norris 2013; deSzoeke et al. 2016). Observational studies focused specifically on trade cumulus exhibit relationships of low clouds to cloud-controlling factors with the same sign as in M17 (Brueck et al. 2015; Nuijens et al. 2015). In conclusion, there is not enough evidence at this time to demonstrate that differing spatial sampling in the observational studies leads to a biased estimate of the mean feedback for tropical low-cloud regions. Further observational studies, particularly for trade cumulus regions, are needed.

The unusual spatial sampling in B16 bears further examination. In B16, the particular locations analyzed vary in time, unlike those in the other studies. Moreover, they obtain a single data point for each month by averaging data across all points they select, no matter how wide their geographical separation. This means the cloud sensitivities they calculate may not necessarily represent a local relationship between cloudiness and SST or EIS.

\subsubsection{I4. Imprecise Statistical Modeling}

A key question is whether clouds vary linearly with their controlling factors. Although low clouds result from the interactions of inherently nonlinear processes, there is ample evidence that a linear approach can explain cloud variations at spatial scales greater than 
$100 \mathrm{~km}$ and time-scales longer than a few days. For example, observations show that a linear relationship with inversion strength can explain over $80 \%$ of the variance in the seasonal cycle of tropical and extra-tropical marine low clouds (Klein and Hartmann 1993; Wood and Bretherton 2006). Over decadal time-scales, Seethala et al. (2015) find that observed tropical low-cloud changes can be well explained with a linear model using SST, $E I S$, and horizontal temperature advection as cloud-controlling factors. In large-eddy simulations, changes in shortwave radiation reflected by low clouds in response to the simultaneous changes in many cloud-controlling factors are within $10 \%$ of the linear sum of changes in simulations forced by individual cloud-controlling factors (Bretherton et al. 2013).

There is a hazard in applying any statistical model "out of sample," an inherent risk whenever sensitivities inferred from a system's variability are used to infer information about the system's response to a perturbation. But this does not appear to be an important concern for low-cloud-controlling factors. In tropical subsidence regions, both inter-annual variability in SST (1-2 K two standard deviations, Deser et al. 2010) and the amplitude of its seasonal cycle (2-4 K, Shea et al. 1992) are generally comparable in magnitude to the $2-3 \mathrm{~K}$ increases typical of a response to $\mathrm{CO}_{2}$ doubling. If cloud changes are indeed linear within the ranges of variability and climate change, the cloud sensitivities derived from variability ought to approximately agree with those associated with climate change. The reviewed studies find approximate agreement when we compare the actual cloud feedback simulated by the climate model to that predicted by (3) when the sensitivities to each factor are derived from each model's simulation of current climate variability. Figure 2a of M16 shows that the linear model of (3) gives a very good prediction for the actual cloud feedback for those climate models whose cloud sensitivities are closer to observations, but less so for the climate models with more erroneous cloud sensitivities. Clouds in the latter models are likely sensitive to cloudcontrolling factors not found in nature and also excluded from the linear prediction model. This good agreement (sometime regardless of model fidelity) was also found by Z15, Q15, and B16, although in some instances the feedback from (3) overestimates the actual feedback. The across-model agreement between cloud variability in the current climate and the cloud feedback to climate change illustrates a type of "emergent constraint" relationship (Klein and Hall 2015). This range of evidence provides support for a linear model of tropical low-cloud changes, although residuals between the actual cloud feedback and that predicted by (3) should be expected.

\subsubsection{I5. Incomplete Set of Cloud-Controlling Factors}

The number of factors used varies across the reviewed studies (Table 2); in Q15 and $\mathrm{B} 16$, one can directly examine the sensitivity to this issue. Q15 arrive at similar predictions whether they use two or seven factors, although the climate-model-predicted feedback with seven factors would be 15-30\% smaller than the feedback predicted with two factors (SST and EIS). This is consistent with M16's result that the factors other than SST and EIS produce small negative feedbacks (Fig. 2b) whose collective sum is $-0.4 \mathrm{~W} \mathrm{~m}^{-2} \mathrm{~K}^{-1}$. B16 find that $\frac{\partial C}{\partial S S T}$ is $\sim 30 \%$ smaller when a two-factor (SST and $E I S)$ regression model is used instead of a single factor (SST), consistent with the general anti-correlation of SST and EIS within natural climate variability. This suggests that studies (Z15, B16, Q15 two-factor model shown in Fig. 3, M17) calculating feedbacks 
with a reduced set of cloud-controlling factors may have a small positive bias in their predicted low-cloud feedback.

\section{Summary and Final Remarks}

Tropical low-cloud feedback is a key uncertainty for climate change. In this paper, we reviewed recent studies that predict the tropical low-cloud feedback using the observed sensitivities of clouds to controlling factors of the large-scale environment. The strength of this approach is that it relies primarily on observations of the cloud response to controlling factors and does not depend on the simulation of clouds by climate models. (It does rely on model predictions of how the controlling factors change with climate, however.) Although we only discuss studies of tropical low clouds, there is also evidence that this approach would also be useful for predicting and understanding low cloud amount and reflectivity feedbacks over the middle-latitude oceans (Gordon and Klein 2014; Ceppi et al. 2016; Terai et al. 2016; Grise and Medeiros 2017).

Studies taking this approach agree that the tropical low-cloud feedback is positive. Our synthesis of the results from these studies is that the contribution of tropical low clouds to the global mean cloud feedback is $0.25 \pm 0.18 \mathrm{~W} \mathrm{~m}^{-2} \mathrm{~K}^{-1}$, indicating that climate models with negative tropical low-cloud feedbacks are implausible. Our synthesis suggests a central estimate for climate sensitivity of $3.0 \mathrm{~K}$. Longer observational records offer perhaps the best near-term prospects for reducing uncertainty, but ultimately smaller uncertainties would also require greater certainty in the prediction of climate changes in cloud-controlling factors. More observational studies targeting trade cumulus regions would also be desirable (Brueck et al. 2015; Bony et al. 2017).

Our observational estimate of tropical low-cloud feedback is consistent with independent estimates from large-eddy simulation models forced by climate-model-simulated changes in cloud-controlling factors. The range of local cloud feedbacks from large-eddy simulations is $0.3-2.3 \mathrm{~W} \mathrm{~m}^{-2} \mathrm{~K}^{-1}$ (Fig. 3). This overlaps reasonably well with our observational estimate of the local cloud feedback of $0.3-1.7 \mathrm{~W} \mathrm{~m}^{-2} \mathrm{~K}^{-1}$.

Even if we know what the tropical low-cloud feedback should be based upon observations and large-eddy simulations, getting climate models to reproduce a feedback of this magnitude is not straightforward. Although some climate models are in agreement with our estimate of the tropical low-cloud feedback, it remains to be seen if they are in agreement for the right reasons. This motivates additional research to understand the physical basis for the cloud sensitivities (particularly for $\frac{\partial C}{\partial S S T}$ ) through both observations (Brient et al. 2016) and large-eddy simulations (Bretherton and Blossey 2014), and whether the physics is correctly modeled in global climate models (Zhang et al. 2013; Sherwood et al. 2014; Vial et al. 2017

Acknowledgements This paper arises from the International Space Science Institute workshop on "Clouds and water vapor, circulation and climate sensitivity." The first author thanks Daniel McCoy, Tim Myers, Xin Qu, and Mark Zelinka for discussions and calculations related to the details of their papers. The first author thanks Louise Nuijens, Bjorn Stevens, and Mark Webb for their review of this paper. The efforts of SAK and AH are supported by the Regional and Global Climate Modeling program of the United States Department of Energy's Office of Science under a project entitled under the project "Identifying Robust Cloud Feedbacks in Observations and Models." RP is grateful for financial support from the US National Science Foundation under award AGS-1138394. The efforts of SAK were performed under the auspices of the United States Department of Energy by Lawrence Livermore National Laboratory under contract DEAC52-07NA27344. 
Open Access This article is distributed under the terms of the Creative Commons Attribution 4.0 International License (http://creativecommons.org/licenses/by/4.0/), which permits unrestricted use, distribution, and reproduction in any medium, provided you give appropriate credit to the original author(s) and the source, provide a link to the Creative Commons license, and indicate if changes were made.

\section{Appendix: Details Used in Synthesizing Studies}

In order for Fig. 3 to provide a meaningful comparison of feedbacks between studies, the original estimates must be converted into a common measure. The common measure is the local cloud feedback: namely by how much the absorbed local net radiation at the top-ofatmosphere in tropical low-cloud regions changes per degree increase in the global mean surface air temperature, as given by (3). We also aim to synchronize error bars so that they each represent $90 \%$ confidence intervals, the typical confidence interval used in Intergovernmental Panel on Climate Change reports.

In this synthesis, there are two common issues affecting multiple studies. First, all observational studies except M16 only provide estimates of the cloud sensitivities $\frac{\partial C}{\partial x_{i}}$, so we must supply values of the cloud-controlling factor changes $\frac{\mathrm{d} x_{i}}{\mathrm{~d} T_{\mathrm{g}}}$ in (3). We specify that $\frac{\mathrm{d} S S T}{\mathrm{~d} T_{\mathrm{g}}}$, the ratio of changes in local $S S T$ to changes in global mean surface air temperature, $T_{\mathrm{g}}$, is 0.7 which is a typical value for climate model simulations of climate warming (Andrews et al. 2015). A value less than unity reflects model predictions of greater warming over land relative to oceans, high latitudes relative to low latitudes, and (least important) tropical ascent regions relative to tropical subsidence regions. We also specify that $\frac{\mathrm{d} E I S}{\mathrm{~d} T_{\mathrm{g}}}=0.14$, matching climate model results that the ratio of temperature-mediated EIS changes to local SST increases in tropical subsidence regions is around 20\% (Webb et al. 2013; Qu et al. 2015a).

Second, questions arise whether the cloud sensitivities measured with observations of either "cloud fraction" (in Q15, Z15, and M17) or "cloud-radiative effect" (in M16 and B16) are a direct measure of the impact of tropical low clouds on the top-of-atmosphere radiation budget. Tropical low clouds have only a small impact on the top-of-atmosphere longwave radiation budget, so we focus on determining the impacts of tropical low clouds on the shortwave radiation budget. The use by M16 and B16 of the shortwave cloudradiative effect (which is defined as clear-sky fluxes minus all-sky fluxes) as a surrogate for these cloud impacts is known to be a good approximation since clear-sky shortwave radiation undergoes relatively smaller changes over the ice-free oceans (Hakuba et al. 2016). However, the results are less clear when using observations of cloud fraction since cloud feedbacks may also result from changes in other cloud properties, especially the distribution of optical thickness (Zelinka et al. 2012). Cloud fraction itself is also relatively sensitive to details of the observing system (Maddux et al. 2010; Pincus et al. 2012) and how this system changes over time (Norris and Evan 2015). Nonetheless, these concerns are somewhat mitigated by the fact that the observed variability in cloud reflectance in tropical low-cloud regions is primarily driven by changes in low-cloud fraction (Klein and Hartmann 1993; George and Wood 2010). To that end, we convert the cloud fraction sensitivities from Q15, Z15, and M17 into cloud feedbacks by multiplying by the sensitivity of the top-of-atmosphere radiation budget to a unit increase in low-cloud fraction. In particular, we use a $1 \mathrm{~W} \mathrm{~m}^{-2}$ decrease per \% increase in low-cloud fraction based upon Klein and Hartmann (1993) who analyzed the relationship between top-of-atmosphere net radiation and ISCCP cloud fraction in tropical low-cloud regions. We note this factor is 
within $10 \%$ of an average factor derived by comparing cloud-radiative effect sensitivities to CALIPSO-GOCCP cloud fraction sensitivities (Tables 2, 3 of B16).

We now present the study-specific details used to derive the estimates shown in Fig. 3.

\section{Q15}

The cloud feedback for Q15 is calculated using the reported values from different satellite cloud observations of the cloud sensitivities $\frac{\partial C}{\partial S S T}$ and $\frac{\partial C}{\partial E I S}$ (Table S4 of Q15), together with our specified values of $\frac{\mathrm{d} S S T}{\mathrm{~d} T_{\mathrm{g}}}$ and $\frac{\mathrm{d} E I S}{\mathrm{~d} T_{\mathrm{g}}}$. The $5-95 \%$ confidence intervals for total sensitivity are calculated assuming that Q15's reported values of 90\% confidence intervals for the sensitivities $\frac{\partial C}{\partial S S T}$ and $\frac{\partial C}{\partial E I S}$ (scaled by 0.2 ) add in quadrature. This assumes that EIS and SST are normally distributed and uncorrelated. Finally, we convert Q15 measures of low-cloud fraction into cloud feedbacks by multiplying by the $-1 \mathrm{~W} \mathrm{~m}^{-2}$ per $\%$ cloud fraction factor.

\section{Z15}

Z15 determine from seasonal cycle satellite observations that low-cloud fraction decreases at a rate of $1.28 \%$ cloud fraction per degree SST increase with a 3-sigma (standard deviation) uncertainty of $0.56 \%$ cloud fraction per degree. For a $90 \%$ confidence interval, the uncertainty would be equal to 1.81 times the standard deviation of the slope estimate, assuming that the slopes are governed by a Student's $t$ distribution with 10 degrees of freedom (= 2 less than the 12 months used in a regression). Thus, we estimate that the $90 \%$ uncertainty in this slope is $0.56^{*}(1.81 / 3)=0.34 \%$ cloud fraction per degree. As $S S T$ is the only cloud-controlling factor in $\mathrm{Z15}$, this slope is equal to the climate change time-scale cloud fraction sensitivity and a cloud feedback can be computed by multiplying by $\frac{\mathrm{d} S S T}{\mathrm{~d} T_{\mathrm{g}}}=0.7$ and the $-1 \mathrm{~W} \mathrm{~m}^{-2}$ per \% cloud fraction factor. This yields a value of $+0.90 \pm 0.24 \mathrm{~W} \mathrm{~m}^{-2} \mathrm{~K}^{-1}$ to the $90 \%$ confidence interval of the local low-cloud feedback from $\mathrm{Z} 15$.

\section{M16}

M16 report a local tropical cloud feedback of $+0.4 \pm 0.9 \mathrm{~W} \mathrm{~m}^{-2} \mathrm{~K}^{-1}$. This estimate combines separate estimates from two independent observational datasets in two different time periods. In order to illustrate the level of agreement, we show the results for each dataset separately. Tim Myers kindly provided these estimates which are $+0.7 \pm 1.7 \mathrm{~W} \mathrm{~m}^{-2} \mathrm{~K}^{-1}$ for ISCCP-FD and $+0.3 \pm 1.1 \mathrm{~W} \mathrm{~m}^{-2} \mathrm{~K}^{-1}$ for CERES-EBAF. We make two modifications to convert these estimates into our desired quantity. First, the confidence intervals in M16 are 95\% confidence intervals calculated assuming perfect knowledge of the changes in cloud-controlling factors, and $95 \%$ uncertainty in the sensitivities of clouds to controlling factors. We convert the uncertainty estimates to $90 \%$ confidence intervals by multiplying by $(1.645 / 1.96)$, the ratio of the $t$-distribution standard variables corresponding to 90 and $95 \%$ confidence intervals for large number samples. Second, M16 calculate cloud feedbacks from the difference between year 121-140 of the abrupt quadrupling of $\mathrm{CO}_{2}$ climate model experiment and a control integration, so that differences in cloud-controlling factors result not only from increases in temperature but also from adjustments to the $\mathrm{CO}_{2}$ radiative forcing (Gregory and Webb 2008; Sherwood 
et al. 2015). Thus, the M16 "feedback" includes cloud changes from rapid adjustments in cloud-controlling factors that needs to be removed in order to have an improved estimate of the temperature-mediated changes in the cloud feedback as represented by (3). The most significant of the cloud adjustments to remove from M16 are those in response to the rapid adjustment of EIS. From the difference of the two climate states, M16 estimate an EIS change of $\frac{\mathrm{d} E I S}{\mathrm{~d} T_{\mathrm{g}}}=0.28$. As this is twice of our desired value of that $\frac{\mathrm{d} E I S}{\mathrm{~d} T_{\mathrm{g}}}=0.14$, the $E I S$ component of the temperature-mediated cloud feedback in M16 is overestimated by a factor of two. Using M16's reported sensitivity of top-of-atmosphere shortwave cloudradiative effect to EIS, we calculate that the M16 feedback should further be adjusted upward by $0.5 \mathrm{~W} \mathrm{~m}^{-2} \mathrm{~K}^{-1}$. With this second change, we arrive at our estimates of $+1.2 \pm 1.4 \mathrm{~W} \mathrm{~m}^{-2} \mathrm{~K}^{-1}$ for ISCCP-FD and $+0.8 \pm 0.9 \mathrm{~W} \mathrm{~m}^{-2} \mathrm{~K}^{-1}$ for CERES-EBAF for the $90 \%$ confidence intervals of the local low-cloud feedback from M16.

\section{B16}

Table 5 of B16 reports the sensitivity of the albedo cloud-radiative effect to two cloudcontrolling factors, SST and EIS, using de-seasonalized variations and variations bandpassed filtered to 3 time-scales. To recover the cloud feedback of (3), we use our specified values of $\frac{\mathrm{d} S S T}{\mathrm{~d} T_{\mathrm{g}}}$ and $\frac{\mathrm{d} E I S}{\mathrm{~d} T_{\mathrm{g}}}$, and then multiply the sum by the average insolation of $387.9 \mathrm{~W} \mathrm{~m}^{-2}$ that B16 calculates for their examined regions. The central estimate of the calculated cloud feedback shown in Fig. 3 is produced using their central estimate of the cloud sensitivities. B16 also report $90 \%$ confidence intervals for these sensitivities. But because B16 use a boot-strap procedure, their confidence intervals are not symmetric about the central estimate. In order to produce $90 \%$ confidence intervals for the cloud feedback which are also asymmetric about their central estimate, the following approximate procedure was used. First a provisional lower bound is calculated using the lower bounds for the EIS and SST sensitivities. Likewise, a provisional upper bound is calculated using the upper bounds for the EIS and SST sensitivities. At the same time, we calculate our target value of the difference between the 5th and 95th percentiles of the cloud feedback distribution by assuming that the 5th-95th percentile difference in the SST and EIS (scaled by 0.2 ) sensitivities add in quadrature. We then modify our provisional upper and lower bounds such that the difference between upper and lower bounds equals our target value of the difference between the 5th and 95th percentiles without changing the mean value of the upper and lower bounds. By this procedure, we recover approximate $90 \%$ confidence intervals for the cloud feedback that are asymmetric about the central estimate.

\section{M17}

M17 use their observed estimates of the sensitivity of cloud to EIS and SST to calculate a cloud fraction change for a 1 degree rise in local SST and 0.2 degree rise in EIS. As the ratio of EIS to SST changes is the same as our desired value, we only need to multiply their estimates by $\frac{\mathrm{d} S S T}{\mathrm{~d} T_{\mathrm{g}}}=0.7$ and the $-1 \mathrm{~W} \mathrm{~m}^{-2}$ per \% cloud fraction factor to yield the local cloud feedback according to (3). Their cloud sensitivities are calculated from observations in three types of regions: (a) 4 latitude bands between $40^{\circ} \mathrm{N}$ and $40^{\circ} \mathrm{S}$, (b) 5 regions with predominately trade cumulus clouds, and (c) 5 regions that contain a mix of stratocumulus and trade cumulus clouds. M17 do not calculate any confidence intervals, and thus in Fig. 3 we report all their estimates without $90 \%$ confidence intervals. 


\section{Large-Eddy Simulation Cloud Feedbacks}

For large-eddy simulations, we use the estimates of local cloud feedback from Table 1 of Bretherton (2015) along with his characterization of cloud regime simplified to either stratocumulus or trade cumulus. For simplicity, we characterize the LES for his transition regime as stratocumulus. We also include the estimate from the large-eddy simulation of precipitating trade cumulus in Vogel et al. (2016). Per degree of local SST, their simulations have a radiation change that spans the range of $0.3-0.55 \mathrm{~W} \mathrm{~m}^{-2} \mathrm{~K}^{-1}$. We assign the feedback from this study to the midpoint of this range and multiply by $\frac{d S S T}{d T_{\mathrm{g}}}=0.7$ to arrive at a value of the local cloud feedback of $0.3 \mathrm{~W} \mathrm{~m}^{-2} \mathrm{~K}^{-1}$ for this study. We note that the exact environmental changes forcing the large-eddy simulations vary in these studies. For example, some simulations omit changes to EIS (Vogel et al. 2016), while others may include changes in additional environmental parameters such as wind speed, subsidence and $\mathrm{CO}_{2}$ concentration (Bretherton 2015). Comparison is justified based upon the expectation that the temperature response is the dominant factor contributing to the cloud feedback.

\section{Global Climate Model Cloud Feedbacks}

Figure 3 shows a range of climate model feedbacks for tropical low-cloud regions. This estimate was derived from Q15, Z15, M16 (second column of panel a in Fig. 2), and B16, each of whom examined the cloud responses to climate change simulated by climate models in each of their studied regions. Because the regions studied differ, the estimates of cloud feedback from climate models will differ. The cloud feedback estimates may also differ because these studies examined different model ensembles (Coupled Model Intercomparison Project Version 3 vs. Version 5), model experiments (scenarios such as A1B or the Representative Concentrations Pathway 4.5 or 8.5 versus idealized experiments such as the abrupt quadrupling or $1 \%$ per year increase of $\mathrm{CO}_{2}$ ), and model variables (cloud fraction versus shortwave cloud-radiative effect). Cloud fraction sensitivities are converted to cloud feedbacks by multiplying by the previously mentioned factor of $-1 \mathrm{~W} \mathrm{~m}^{-2}$ per $\%$ cloud fraction. This is appropriate because Fig. 2 of Qu et al. (2014) showed that in climate models the sensitivity of the top-of-atmosphere shortwave cloud-radiative effect to cloud fraction in tropical low-cloud regions is close to this factor. The differing model experiments means that the rapid cloud adjustments to $\mathrm{CO}_{2}$ are included in some studies. In addition to these four estimates, we also consider the average cloud feedbacks in tropical subsidence regions calculated from the abrupt $\mathrm{CO}_{2}$ quadrupling simulations analyzed in Caldwell et al. (2016). These feedbacks primarily reflect the shortwave feedbacks from low clouds due to the absence of upper-level clouds. Despite these differences, the upper and lower bounds of the climate model values across the five studies differ by no more than $0.7 \mathrm{~W} \mathrm{~m}^{-2} \mathrm{~K}^{-1}$ from the multi-study mean values of -0.8 and $+1.8 \mathrm{~W} \mathrm{~m}^{-2} \mathrm{~K}^{-1}$ shown in Fig. 3.

\section{References}

Andrews T, Gregory JM, Webb MJ (2015) The dependence of radiative forcing and feedback on evolving patterns of sea surface temperature change in climate models. J Clim 28:1630-1648. doi:10.1175/ JCLI-D-14-00545.1 
Bellomo K, Clement A, Mauritsen T, Radel G, Stevens B (2014) Simulating the role of subtropical stratocumulus clouds in driving Pacific climate variability. J Clim 27:5119-5131. doi:10.1175/JCLI-D-1300548.1

Bellomo K, Clement A, Mauritsen T, Radel G, Stevens B (2015) The influence of cloud feedbacks on Equatorial Atlantic variability. J Clim 28:2725-2744. doi:10.1175/JCLI-D-14-00495.1

Blossey PN et al (2013) Marine low cloud sensitivity to an idealized climate change: the CGILS LES intercomparison. J Adv Model Earth Syst. doi:10.1002/jame.20025

Bony S, Dufresne J-L (2005) Marine boundary layer clouds at the heart of tropical cloud feedback uncertainties in climate models. Geophys Res Lett 32:L20806. doi:10.1029/2005GL023851

Bony S, Stevens B, Ament F, Bigorre S, Chazette P, Crewell S, Delanoe J, Emanuel K, Farrell D, Flamant C, Gross S, Hirsch L, Karstensen J, Mayer B, Nuijens L, Ruppert Jr. JH, Sandu I, Siebesma P, Speich S, Szczap F, Totems J, Vogel R, Wendisch M, Wirth M (2017) EUREC ${ }^{4}$ A: a field campaign to elucidate the couplings between clouds, convection and circulation. Surv Geophys. doi:10.1007/ s10712-017-9428-0

Boucher O et al (2013) Clouds and aerosols. In: Stocker TF, Qin D, Plattner G-K, Tignor M, Allen SK, Boschung J, Nauels A, Xia Y, Bex V, Midgley PM (eds) Climate change 2013: the physical science basis. Contribution of working group I to the fifth assessment report of the intergovernmental panel on climate change. Cambridge University, Cambridge, pp 571-657

Bretherton CS (1993) Understanding Albrecht's model of trade cumulus cloud fields. J Atmos Sci 50:2264-2283

Bretherton CS (2015) Insights into low-latitude cloud feedbacks from high-resolution models. Philos Trans R Soc A. doi:10.1098/rsta.2014.0415

Bretherton CS, Blossey PN (2014) Low cloud reduction in a greenhouse-warmed climate: results from Lagrangian LES of a subtropical marine cloudiness transition. J Adv Model Earth Syst. doi:10.1002/ 2013MS000250

Bretherton CS, Blossey PN, Jones CR (2013) Mechanisms of marine low cloud sensitivity to idealized climate perturbations: a single-LES exploration extending the CGILS cases. J Adv Model Earth Syst 5:316-337

Brient F, Schneider T (2016) Constraints on climate sensitivity from space-based measurements of lowcloud reflection. J Clim 29:5821-5834. doi:10.1175/JCLI-D-15-00897.1

Brient F, Schneider T, Tan Z, Bony S, Qu X, Hall A (2016) Shallowness of tropical low clouds as a predictor of climate models' response to warming. Clim Dyn 47:433-449. doi:10.1007/s00382-015-2846-0

Brueck M, Nuijens L, Stevens B (2015) On the seasonal and synoptic time-scale variability of the North Atlantic trade wind region and its low-level clouds. J Atmos Sci 72:1428-1446

Caldwell PM, Bretherton CS (2009) Response of a subtropical stratocumulus-capped mixed layer to climate and aerosol changes. J Clim 22:20-38. doi:10.1175/2008JCLI1967.1

Caldwell PM, Zelinka MD, Taylor KE, Marvel K (2016) Quantifying the sources of intermodel spread in equilibrium climate sensitivity. J Clim 29:513-524. doi:10.1175/JCLI-D-15-00352.1

Ceppi P, McCoy DT, Hartmann DL (2016) Observational evidence for a negative shortwave cloud feedback in middle to high latitudes. Geophys Res Lett 43:1331-1339. doi:10.1002/2015GL067499

Chepfer H, Bony S, Winker D, Cesana G, Dufresne J, Minnis P, Stubenrauch C, Zeng S (2010) The GCMoriented CALIPSO cloud product (CALIPSO-GOCCP). J Geophys 115:D00H16. doi:10.1029/ 2009JD012251

Christensen MW, Carri GG, Stephens GL, Cotton WR (2013) Radiative impacts of free-tropospheric clouds on the properties of marine stratocumulus. J Atmos Sci 70:3102-3118. doi:10.1175/JAS-D-12-0287.1

Deser C, Alexander MA, Xie S-P, Phillips AS (2010) 2010: sea surface temperature variability: patterns and mechanisms. Ann Rev Mar Sci 2:115-143. doi:10.1146/annurev-marine-120408-151453

De Szoeke SP, Verlinden KL, Yuter SE, Mechem DB (2016) The time scales of variability of marine low clouds. J Clim 29:6463-6481. doi:10.1175/JCLI-D-15-0460.1

Dufresne J-L, Bony S (2008) An assessment of the primary sources of spread of global warming estimates from coupled atmosphere-ocean models. J Clim 21:5135-5144. doi:10.1175/2008JCLI2239.1

Foster MJ, Heidinger A (2013) PATMOS-x: results from a diurnally corrected 30-yr satellite cloud climatology. J Clim 26:414-425. doi:10.1175/JCLI-D-11-00666.1

George RC, Wood R (2010) Subseasonal variability of low cloud properties over the southeast Pacific Ocean. Atmos Chem Phys 10:4047-4063. doi:10.5194/acp-10-4047-2010

Gordon ND, Klein SA (2014) Low-cloud optical depth feedback in climate models. J Geophys Res Atmos 119:6052-6065

Gregory JM, Andrews T (2016) Variation in climate sensitivity and feedback parameters during the historical period. Geophys Res Lett 43:3911-3920. doi:10.1002/2016GL068406 
Gregory JM, Webb M (2008) Tropospheric adjustment induces a cloud component in $\mathrm{CO}_{2}$ forcing. J Clim 21:58-71. doi:10.1175/2007JCLI1834.1

Grise KM, Medeiros B (2017) Understanding the varied influence of mid-latitude jet position on clouds and cloud radiative effects in observations and global climate models. J Clim. doi:10.1175/JCLI-D-1600295.1 (in press)

Hakuba MZ, Folini D, Wild M (2016) On the zonal near-constancy of fractional solar absorption in the atmosphere. J Clim 29:3423-3440. doi:10.1175/JCLI-D-15-0277.1

Klein SA, Hall A (2015) Emergent constraints for cloud feedbacks. Curr Clim Change Rep 1:276-287. doi: 10.1007/s40641-015-0027-1

Klein SA, Hartmann DL (1993) The seasonal cycle of low stratiform clouds. J Clim 6:1587-1606. doi:10. 1175/1520-0442(1993)006,1587:TSCOLS.2.0.CO;2

Klein SA, Hartmann DL, Norris JR (1995) On the relationships among low-cloud structure, sea surface temperature, and atmospheric circulation in the summertime Northeast Pacific. J Clim 8:1140-1155

Klein SA (1997) Synoptic variability of low-cloud properties and meteorological parameters in the subtropical trade wind boundary layer. J Clim 10:2018-2039. doi:10.1175/1520-0442(1997)010<2018: SVOLCP $>2.0 . \mathrm{CO} ; 2$

Loeb N, Wielicki B, Doelling D, Smith G, Keyes D, Kato S, Manalo-Smith N, Wong T (2009) Toward optimal closure of the Earth's top-of-atmosphere radiation budget. J Clim 22:748-766. doi:10.1175/ 2008JCLI2637.1

Mace GG, Zhang Q, Vaughan M, Marchand R, Stephens G, Trepte C, Winker D (2009) A description of hydrometeor layer occurrence statistics derived from the first year of merged Cloudsat and CALIPSO data. J Geophys Res 114:D00A26. doi:10.1029/2007JD009755

Maddux BC, Ackerman SA, Platnick S (2010) Viewing geometry dependencies in MODIS cloud products. J Atmos Ocean Technol 27:1519-1528. doi:10.1175/2010JTECHA1432.1

Marchand R, Ackerman TP (2010) An analysis of cloud cover in multiscale modeling framework global climate model simulations using 4 and $1 \mathrm{~km}$ horizontal grids. J Geophys Res 115:D16207. doi:10. 1029/2009JD013423

Mauger GS, Norris JR (2010) Assessing the impact of meteorological history on subtropical cloud fraction. J Clim 23:2926-2940. doi:10.1175/2010JCLI3272.1

McCoy DT, Eastman R, Hartmann DL, Wood R (2017) The change in low-cloud cover in a warmed climate inferred from AIRS, MODIS, and ECMWF-interim analyses. J Clim. doi:10.1175/JCLI-D-15-0734.1 (in press)

Myers TA, Norris JR (2013) Observational evidence that enhanced subsidence reduces subtropical marine boundary layer cloudiness. J Clim 26:7507-7524. doi:10.1175/JCLI-D-12-00736.1

Myers TA, Norris JR (2016) Reducing the uncertainty in subtropical cloud feedback. Geophys Res Lett 43:2144-2148. doi:10.1002/2015GL067416

Norris JR, Evan AT (2015) Empirical removal of artifacts from the ISCCP and PATMOS-x satellite cloud records. J Atmos Ocean Technol 32:691-702. doi:10.1175/JTECH-D-14-00058.1

Norris JR, Iacobellis SF (2005) North Pacific cloud feedbacks inferred from synoptic-scale dynamic and thermodynamic relationships. J Clim 18:4862-4878. doi:10.1175/JCLI3558.1

Nuijens L, Medeiros B, Sandu I, Ahlgrimm M (2015) Observed and modeled patterns of covariability between low-level cloudiness and the structure of the trade-wind layer. J Adv Model Earth Syst 7:1741-1764. doi:10.1002/2015MS000483

Pincus R, Platnick S, Ackerman SA, Hemler RS, Hofmann RJP (2012) Reconciling simulated and observed views of clouds: MODIS, ISCCP, and the limits of instrument simulators. J Clim 25:4699-4720. doi:10.1175/JCLI-D-11-00267.1

Pincus et al (this issue) The distribution of water vapor over low-latitude oceans: current best estimates, errors, and impacts. Surv Geophy (in press)

Platnick S, King MD, Ackerman SA, Menzel WP, Baum BA, Riedi JC, Frey RA (2003) The MODIS cloud products: algorithms and examples from Terra. IEEE Trans Geosci Remote Sens 41:459-473. doi:10. 1109/TGRS.2002.808301

Qu X, Hall A, Klein SA, Caldwell PM (2014) On the spread of changes in marine low cloud cover in climate model simulations of the 21st century. Clim Dyn 42:2603-2626. doi:10.1007/s00382-013-1945-z

Qu X, Hall A, Klein SA, Caldwell PM (2015a) The strength of the tropical inversion and its response to climate change in 18 CMIP5 models. Clim Dyn 45:375-396. doi:10.1007/s00382-014-2441-9

Qu X, Hall A, Klein SA, DeAngelis AM (2015b) Positive tropical marine low-cloud cover feedback inferred from cloud-controlling factors. Geophys Res Lett 42:7767-7775. doi:10.1002/2015GL065627

Rieck M, Nuijens L, Stevens B (2012) Marine boundary layer cloud feedbacks in a constant relative humidity atmosphere. J Atmos Sci 69:2538-2550 
Rossow WB, Schiffer RA (1999) Advances in understanding clouds from ISCCP. Bull Am Meteorol Soc 80:2261-2287

Rugenstein MAA et al (2016) Multiannual ocean-atmosphere adjustments to radiative forcing. J Clim 29:5643-5659. doi:10.1175/JCLI-D-16-0312.1

Schubert WH, Wakefield JS, Steiner EJ, Cox SK (1979) Marine stratocumulus convection. Part II: horizontally inhomogeneous solutions. J Atmos Sci 36:1308-1324

Seethala C, Norris JR, Myers TA (2015) How has subtropical stratocumulus and associated meteorology changed since the 1980s? J Clim 28:8396-8410. doi:10.1175/JCLI-D-15-0120.1

Shea DJ, Trenberth KE, Reynolds RW (1992) A global monthly sea surface temperature climatology. J Clim 5:987-1001

Sherwood SC, Bony S, DuFresne J-L (2014) Spread in model climate sensitivity traced to atmospheric convective mixing. Nature 505:37-42. doi:10.1038/nature12829

Sherwood SC et al (2015) Adjustments in the forcing-feedback framework for understanding climate change. Bull Am Meteorol Soc 96:228-277. doi:10.1175/BAMS-D-13-00167.1

Stevens B, Brenguier J-L (2009) Cloud-controlling factors: low clouds. In: Heintzenberg J, Charlson R (eds) Clouds in the perturbed climate system. MIT Press, Cambridge, pp 173-196

Stocker TF et al (2013) Technical summary. In: Stocker TF, Qin D, Plattner G-K, Tignor M, Allen SK, Boschung J, Nauels A, Xia Y, Bex V, Midgley PM (eds) Climate change 2013: the physical science basis. Contribution of working group I to the fifth assessment report of the intergovernmental panel on climate change. Cambridge University, Cambridge, pp 33-115

Terai CR, Klein SA, Zelinka MD (2016) Constraining the low-cloud optical depth feedback at middle and high latitudes using satellite observations. J Geophys Res Atmos 121:9696-9716. doi:10.1002/ 2016JD025233

van der Dussen JJ, de Roode SR, Gesso SD, Siebesma AP (2015) An LES model study of the influence of the free tropospheric thermodynamic conditions on the stratocumulus response to a climate perturbation. J Adv Model Earth Syst 7:670-691. doi:10.1002/2014MS000380

Vial J, Bony S, Stevens B, Vogel R (2017) Mechanisms and model diversity of trade-wind shallow cumulus cloud feedbacks: a review. Surv Geophys. doi:10.1007/s10712-017-9418-2

Vogel R, Nuijens L, Stevens B (2016) The role of precipitation and spatial organization in the response to trade-wind clouds to warming. J Adv Model Earth Syst 8:843-862. doi:10.1002/2015MS000568

Webb M, Lambert FH, Gregory JM (2013) Origins of difference in climate sensitivity, forcing, and feedback in climate models. Clim Dyn 40:677-707. doi:10.1007/s00382-012-1336-X

Wood R, Bretherton CS (2006) On the relationship between stratiform low cloud cover and lower-tropospheric stability. J Clim 19:6425-6432. doi:10.1175/JCLI3988.1

Zelinka MD, Klein SA, Hartmann DL (2012) Computing and partitioning cloud feedbacks using cloud property histograms. Part II: attribution to the nature of cloud changes. J Clim 25:3736-3754

Zelinka MD, Zhou C, Klein SA (2016) Insights from a refined decomposition of cloud feedbacks. Geophys Res Lett 43:9249-9259. doi:10.1002/2016GL069917

Zhai C, Jiang JH, Su H (2015) Long-term cloud change imprinted in seasonal cloud variation: more evidence of high climate sensitivity. Geophys Res Lett 42:8729-8737. doi:10.1002/2015GL065911

Zhang Y, Rossow WB, Lacis AA, Oinas V, Mishchenko MI (2004) Calculation of radiative fluxes from the surface to top of atmosphere based on ISCCP and other global data sets: refinements of the radiative transfer model and the input data. J Geophys Res 109:D19105. doi:10.1029/2003JD004457

Zhang M, Bretherton CS, Blossey PN, Bony S, Brient F, Golaz J-C (2012) The CGILS experimental design to investigate low cloud feedbacks in general circulation models by using single-column and largeeddy simulation models. J Adv Model Earth Syst 4:M12001. doi:10.1029/2012MS000182

Zhang M et al (2013) CGILS: results from the first phase of an international project to understand the physical mechanisms of low cloud feedbacks in single column models. J Adv Model Earth Syst. doi:10.1002/2013MS000246

Zhou C, Zelinka MD, Klein SA (2016) Impact of decadal cloud variations on the Earth's energy budget. Nat Geosci 9:871-874. doi:10.1038/ngeo2828 